\title{
Material Constitutive Models for Engineered Cementitious Composites
}

\author{
Youkhanna Zayia Dinkha ${ }^{*}, 1$, James H. Haido ${ }^{1}$ \\ ${ }^{1}$ Department of Civil Engineering, University of Duhok, Kurdistan Region - Iraq,(youkhanna.zayia@uod.ac, \\ james.haido@uod.ac)
}

\begin{abstract}
The necessity for realistic constitutive models that represent ECC's behavior under load grows as research in ECC progresses from material creation to structural applications. Constitutive models of ECC can be used to simulate structural responses when paired with the finite element approach. These simulations are helpful in gaining a better understanding of how ECC's unique features, such as tensile ductility and fracture width controlling, may be translated into enhanced structural performance. In this work, phenomenological models for 1D are presented which includes the constitutive models for plain ECC under tension compression, as well as reinforced beams behavior under bending. The models given lay the groundwork for more growth in this subject, which is desperately needed. as result, monotonic loading applications for specific structures showed their variety, weaknesses were also found. These include the tendency to predict a tougher and stronger structural reaction than experimental findings. This is because the multiple cracks can only deform in the opening mode, but not in the sliding mode.
\end{abstract}

Keywords: ECC, Constitutive Models, Monotonic Loading.

Received: April 14, 2021 / Accepted: June 25, 2021 / Online: June 30, 2021

\section{INTRODUCTION}

The engineered cementitious composite (ECC) corresponds to the broad fiber reinforced concrete (FRC) class [1], since it includes fiber in a cement matrix. However, after the formation of a crack that tends to widen as the load bearing capacity decreases, FRCs experience a tension-softening attitude under tensile loading. The elastic limit for normal concrete as well as FRC is achieved at about 0.01 percent. The relatively recent Ultra-High Performance Concrete (UHPC) class, with optimized granular gradation, emphasizes high compressive strength (over $150 \mathrm{MPa}$ ) and is capable of sustaining $5 \mathrm{MPa}$ post-cracking tensile strength [2-5]. UHPC typically has a potential for tensile stress of $0.2 \%$ or less (Fig. 1 ).

The ECC is a class of ductile-based materials, usually having the potential for tensile strain above 2 percent (Fig. 1)[7-9]. The ECC design basis is also substantially different from the High Strength Concrete (HSC) or UHPC design basis. The mix design for HSC and UHPC are based on the dense packing of particles.

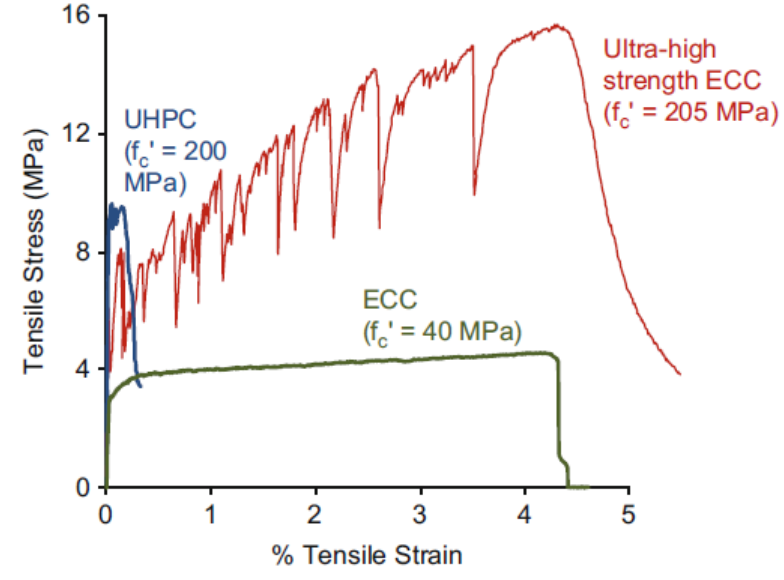

Fig. 1. ECC's efficiency enhances tensile ductility, with such a large variety of feasible compressive power. Usually, ECC's strain potential is over 2 percent or 200 times that of regular concrete or FRC. The compressive strength of the ECC varies from a few MPa to over $200 \mathrm{MPa}$, made to match the various requirements of various applications.[6]. 
The material microstructure of the ECC is, on the other hand, systematically adapted to the synergistic interactions between the microstructural components based on a knowledge group known as ECC micromechanics. In other words, when the composite is loaded, the interface functionality of fiber, matrix and fiber/matrix is purposely designed to interact with each other in a specified way.

The goal form ECC is to control the main faults in conventional concrete, i.e. the lack of potential for tensile deformation. As a consequence, ECC has a stress-strain curve more like metals with a distinctive "yield" strength accompanied via tensile strain-hardening behavior. Through stain-hardening stage, a linear relation with less slopes can be approximated by the stress-strain relationship, the linear relationship with the amount of the specific ECC is noticeable by several load-drops.

ECC is also known as Strain-Hardening Cementitious Composites (SHCC) for this purpose, a name that emphasizes the form of its almost bi-linear tensile stress-strain reaction and its structural design usefulness. Usually, ECC's tensile ductility, the strain capacity at ultimate strength, is two orders of magnitude greater than that of conventional concrete, whereas its compressive strength varies from a few MPa (e.g., highly insulating fire-resistant ECC for steel protection[10] to over 200 $\mathrm{MPa}$ (ultra-high strength and blast resistance ECC[11]). ECC deformability as well as multiple cracking properties are shown in Fig. 2. The ECC's focus on tensile ductility is evident and improves the resilience, durability and sustainability of infrastructure through preventing fracture failure.
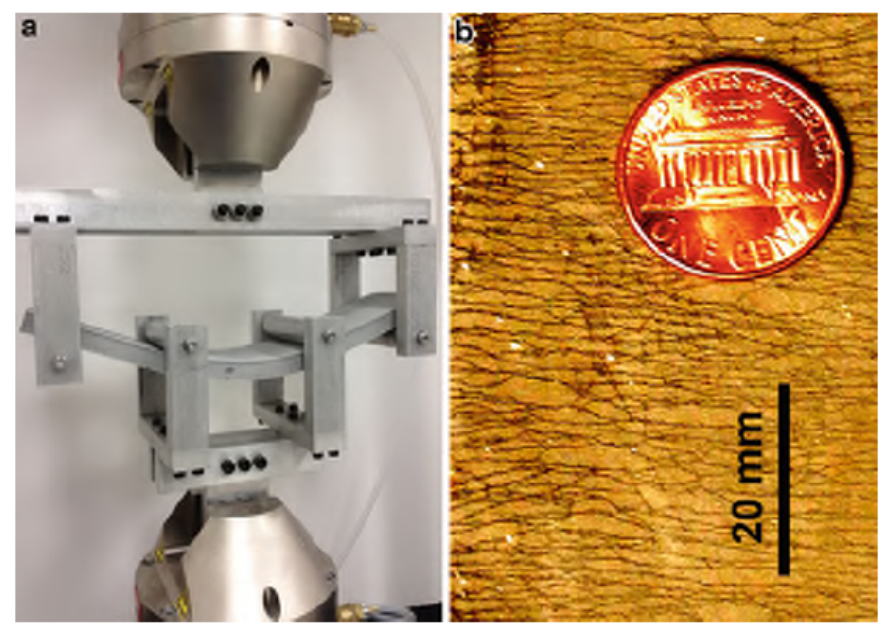

Fig. 2. ECC has high deformability while suppressing brittle fracture. Under (a) bending load and (b) direct tension. Multiple cracking provides the tensile ductility, or "give" to the material when overloaded beyond the elastic state [6].

\section{Mechanical Properties of ECC}

\section{A. Direct Tension}

Evaluating the ECC tensile response includes measuring the uniaxial tensile stress as a function of the material's uniaxial tensile strain. It is distinguished from the indirect tension response obtained from experiments such as the Brazilian test for measuring split-tensile strength or the four-point bending

(FPB) test for calculating the concrete rupture module and FRCs by the direct characterization of the tensile stress-strain response. Nevertheless, unlike these indirect tests, there is no standardize procedure for direct tension test worldwide.

The research community's recent attempts to find consensus on such a standard protocol. (In China and in Japan, standards are available.) For direct tension tests on ECC specimens, two types of planar specimen geometries are usually used, namely dogbones (sometimes often referred to as dumbbells in the literature) and coupons as shown in Fig. 3).
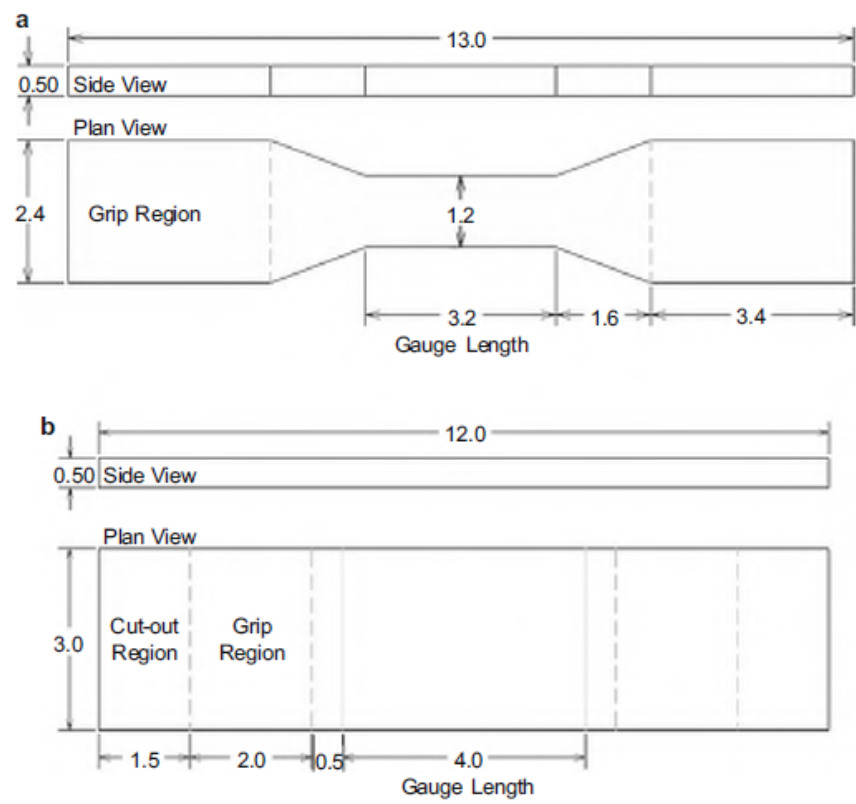

Fig. 3. Planar geometries of ECC specimens for direct tension testing (All dimensions in inches)[6] (a) Dogbone [12] emphasizes stress upon this narrower section along the length of the gauge, thus preventing grip loss, (b) Coupon provides a greater section for improved uniformity of fiber distribution and simplified geometry that prevents accumulation of shrinkage stress during specimen curing.

The stress-strain diagram in direct tension test for a sample of ECC is shown in Fig. 4. The visual state of the ECC sample in this stress-strain curve at five separate stages (a) through (e) is detailed in Fig. 5.

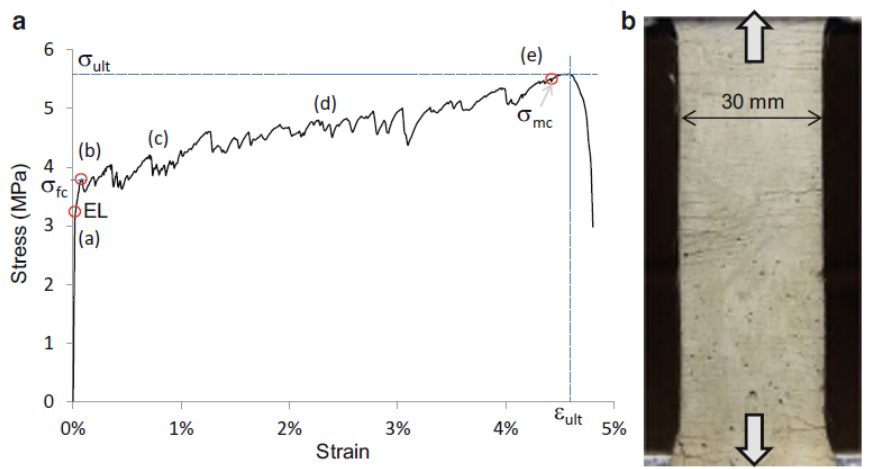

Fig. 4. Characteristic direct tension stress-strain behavior of ECC: (a) stressstrain curve (b) saturated multiple cracking in a dogbone specimen. 


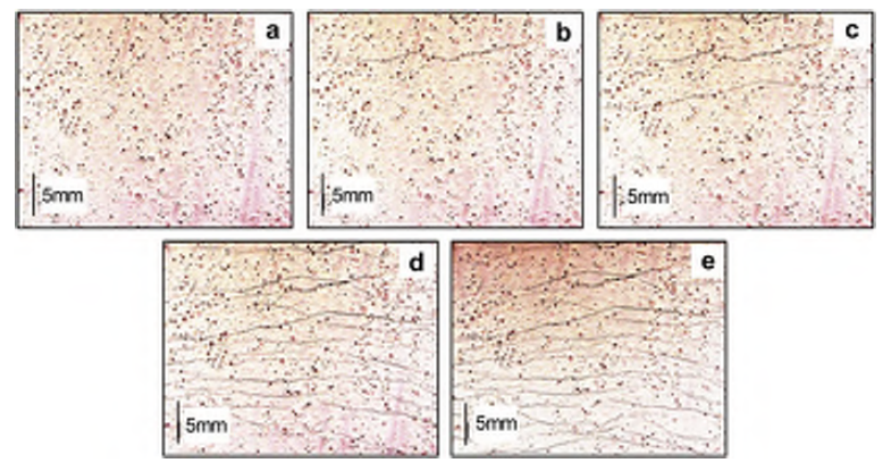

Fig. 5. Development of multiple cracking in an ECC specimen under direct tension. (Note: (a) through (e) stand for various stages of the stress-strain curve in Fig. 4a.

As the load rises from zero, before the elastic limit (EL) is reached, the tensile stress within the composite increases linearelastically. The first crack strength $\sigma$ fcof ECC is slightly greater than the EL. ECC sample starts to weaken between EL and $\sigma$ fc due to the initiation of micro-cracks at this site, the stress intensity factor and the local matric fracture toughness are equals. Due to fiber bridging which requires load increasing to maintain, this stretching is typical considered stable. Whereas tensile stress approached $\sigma$ fc, flat matrix micro-cracks nearly instantaneously spreads through the specimen cross-section. This propagation is satisfactory for multiple cracking energy criterion. At this stage, a slight decrease in the load transfer capacity of the matrix is notice $d$ with a sudden loose in composite section. At the matrix cracking strength, however, the fiber bridging potential is not exceeded and the tensile stress not only recovers but exceeds $\sigma$ fc with increasing tensile strain. The tensile stress increases until the next biggest defect is caused by another micro-crack. This mechanism is repeated and new flat crack is shaped at the weakest bridged section within all cracked section when the fiber bridging strength $\left(\sigma_{-} 0\right)$ is surpassed by the applied tensile stress. The ultimate tensile stress practiced by the specimen throughout this test is termed as the direct tensile strength or ultimate tensile strength ( $\sigma$ ult), besides the corresponding strain value is termed as the tensile strain capacity (cult).

The four-point bending (FPB) is the depended experiment to test the ECC in flexure. It is also known as third-point bending test since this arrangement provides a constant moment within the middle third of the simply supported beam's. The behavior of ECC in flexure is anticipated to be size dependent. Fig. 6 shows the flexural behavior of polyvinyl alcohol fiber PVAECC and polyethylene fiber-reinforced PE-ECC. Their behavior show deflection hardening, i.e., after damage, flexural strength continuous to increase when damage is started. It is also generally known that with age, the flexural strength continuous to increase whereas deflection is reduced at the peak load.
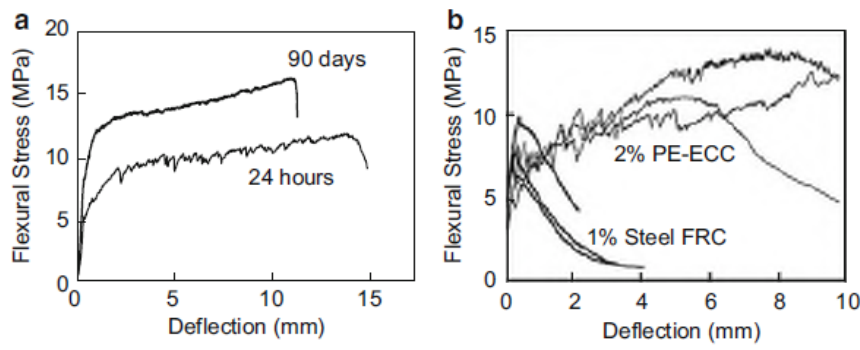

Fig. 6. Typical flexural response of ECC beams (a) PVA-ECC at two ages [13] (b) PE-ECC \& Steel FRC [14]

ECC beams (with no addition of any type of reinforcement) crack pattern under FPB are observed in Fig. 7 [11, 14], the ECC beams show a saturation of flexural cracks about $85 \%$ of the beam total depth in the region of beam of constant moment (confined within the vertical black lines). This behavior of ECC is quite similar to that one for reinforced concrete beams with conventional reinforcement but the cracks are spaced closer in ECC beams. Near the modulus of rupture, the average deflections of the beam are much higher and up to $2.5 \%$ of the beam length. a

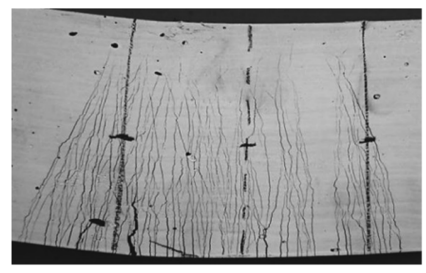

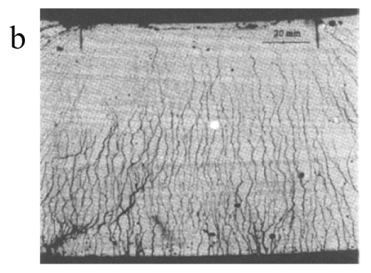

Fig. 7. Crack arrangements in ECC beams (beam depth $=400$ ) under FPB. (a) High strength ECC [11], (b) PE-ECC [14].

Maalej and $\mathrm{Li}$ [14] have investigated the ratio of flexural/tensile strength-deflection and modulus of rupture (MOR) for ECC with traditional beam bending theory. The moment-curvature relationship (M- $\varphi$ ) of the ECC beams was calculated by modeling the uniaxial tensile and compressive behavior as bilinear functions. The main results of this analysis are shown in the Fig. 8 with measured ratios of MOR/ $/ \mathrm{fc}$, $\sigma u l t / \sigma f c$, and $\varepsilon u l t$. The results show proportional limit between $\mathrm{MOR} / \sigma \mathrm{fc}$ and $\sigma \mathrm{ult} / \sigma \mathrm{fc}$ relationship. While the increase rate for the MOR/ $\mathrm{\sigma fc}$ ratio considerably decreases beyond the starin $\varepsilon u l t$ of $1 \%$.
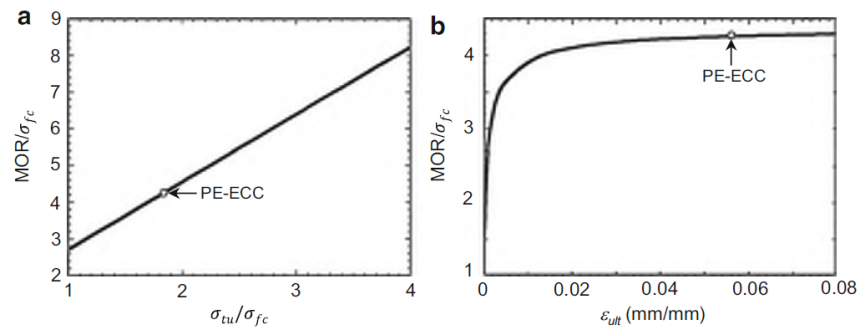

Fig. 8. Computed variation of flexural/first crack strength ratio with (a) ultimate tensile strength, (b) tensile strain capacity[14]

Many researchers have investigated the ECC behavior in compression using standard cubes and cylinders similar to conventional concrete and FRC $[15,16]$. ECC extensively 
varied and classified in to different types, for low strength compressive strength varied between 10-30 MPa this type of ECC was designed for rehabilitation purposes such as fire proofing. Strength range between 40-70 MPa was adopted for most structural uses. While for strength of $150 \mathrm{MPa}$ and above, this ECC is known as ultra-high strength (UHS) was designed for special uses in blast resistance and impact conditions. The maximum compressive strength reached in ECC is $205 \mathrm{MPa}$, with a tensile strain of $3 \%$. Fig. 9 shows the stress-strain relationship for ECC samples under compression. The relation is linear and elastic of about $40-50 \%$ from the ultimate strain for normal ECC samples. While for UHS-ECC the curve was linear for about $80 \%$ which is close to the behavior of the same strengths of HSC/UHPCs. After this limit, the curve increase in a nonlinear and inelastic followed by the development of closely spaced and subparallel vertical cracks. Via fiber-bridging in ECC, such cracks were fixed, resulting in an increase and close the peak in a more ductile approach, rather than a sharp peak usually seen in conventional concrete and FRCs [16].
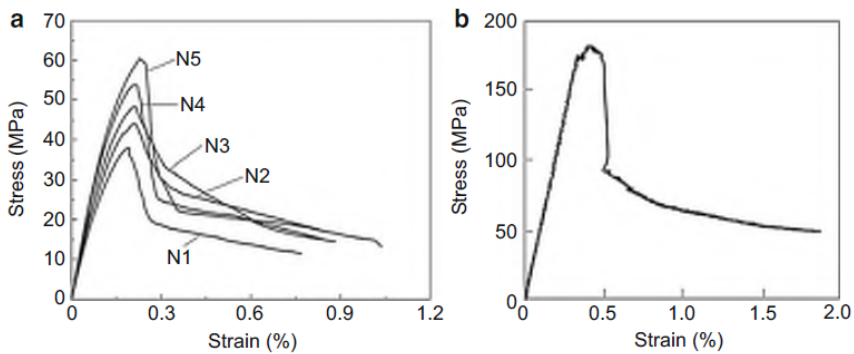

Fig. 9. Compressive behavior of ECC Normal strength ECC (b) ultra-high strength ECC.

The mechanical properties for ECC classes with corresponding ranges are summarized in Table 1.

TABLE I. FOUR BROAD ECC GROUPS WITH THEIR RESPECTIVE SETS OF PROPERTIES[11, 13, 15, 17-21].

\begin{tabular}{l|l|l|l|l}
\hline & FR-ECC & LW-ECC & Normal-ECC & HS-ECC \\
\hline Density $\rho\left(\mathrm{kg} / \mathrm{m}^{3}\right)$ & 550 & $930-1800$ & $1800-2100$ & $2300-2400$ \\
\hline $\begin{array}{l}\text { Young's modulus } \\
\mathrm{E}(\mathrm{GPa})\end{array}$ & $4-6$ & $8-12$ & $15-23$ & $41-48$ \\
\hline $\begin{array}{l}\text { First crack strength } \\
\sigma_{\mathrm{fc}}(\mathrm{MPa})\end{array}$ & $0.8-1$ & $2-4$ & $3-5$ & $8-10$ \\
\hline $\begin{array}{l}\text { Ultimate tensile } \\
\text { strength } \sigma_{\mathrm{ult}}(\mathrm{MPa})\end{array}$ & $1-1.5$ & $2-5$ & $4-8$ & $14-17$ \\
\hline $\begin{array}{l}\text { Tensile strain } \\
\text { capacity }(\%)\end{array}$ & $1-3$ & $2-4$ & $2-8$ & $3-8$ \\
\hline $\begin{array}{l}\text { Compressive } \\
\text { strength } \mathrm{f}_{\mathrm{c}}^{\prime}(\mathrm{MPa})\end{array}$ & $2.5-3.5$ & $20-40$ & $30-80$ & $120-205$ \\
\hline $\begin{array}{l}\text { Compressive strain } \\
\text { capacity } \varepsilon_{\mathrm{ult}}(\%)\end{array}$ & - & - & $0.4-0.5$ & $0.3-0.4$ \\
\hline $\begin{array}{l}\text { Flexural strength } \\
\text { MOR (MPa) }\end{array}$ & - & - & $10-16$ & $28-32$ \\
\hline $\begin{array}{l}\text { Intended } \\
\text { applications }\end{array}$ & $\begin{array}{l}\text { Fire-proofing of } \\
\text { steel structures }\end{array}$ & $\begin{array}{l}\text { Lightweight } \\
\text { applications }\end{array}$ & Structural use & $\begin{array}{l}\text { Impact and blast } \\
\text { resistant structures }\end{array}$ \\
\hline
\end{tabular}

\section{Constitutive Modeling of ECC}

In order to predict structural responses, constitutive model requirements are required. This is useful to optimize structural design by carefully choosing geometry, sizes and materials, including concrete details on properties and reinforcement details, while following the specifications of design code.
Optimization will minimize weight, price, and impact on the environment while preserving protection for planned service loads. In validating structural designs, constitutive models are often of high value without unnecessary innovation which may be costly or impractical especially on the full scale of the structures[6]. Li [22] proposed the integrated design structures and materials (ISMD) strategy, which, in theory, enables structural performance requirements to be related to ECC composite properties and the procurement and customizing of ECC ingredients (Fig. 10). A constitutive model which links composite material properties to structural achievement in conjunction with the finite element method is a critical element for an ISMD approach to be successful.

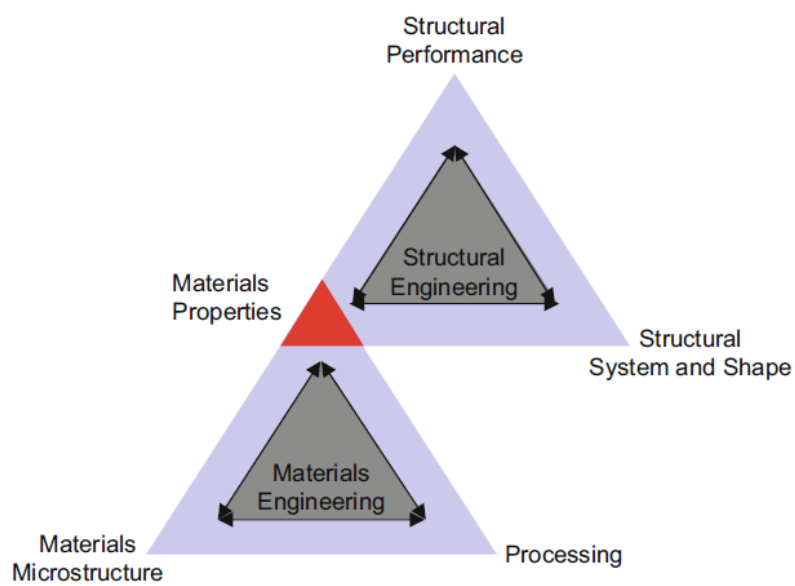

Fig. 10. ISMD relates structural performance to composite properties and microstructure of materials. Constituent models promote the quantitative link.

\section{A. Modeling ECC Beam Behavior}

Assuming that plane sections remain plan during deformation, beams and slabs under bending load may be modeled. Thus, only the uniaxial tensile and compressive constitutive laws of the ECC are required in such a scenario for the modeling of the beam behavior. The behavior of ECC beams with no reinforcement was carried out by Maalej and $\mathrm{Li}$ [14] to study the flexural/tensile ratio.

\section{- Flexural/Tensile Strength Ratio of ECC Beams:}

For a tensile and compressive uniaxial stress-strain bilinear representation ECC Relationship (Figs. 11 and 12).

$$
\begin{aligned}
& \text { In tension, and } \sigma= \begin{cases}\frac{\sigma_{t c}}{\varepsilon_{t c}} \varepsilon & \varepsilon<\varepsilon_{t c} \\
\sigma_{t c}+\frac{\sigma_{t u}-\sigma_{t c}}{\varepsilon_{t u}-\varepsilon_{t c}}\left(\varepsilon-\varepsilon_{t c}\right) & \varepsilon \geq \varepsilon_{t c}\end{cases} \\
& \text { In compression. } \sigma= \begin{cases}2 \frac{\sigma_{c p}}{\varepsilon_{c p}} \varepsilon & \varepsilon<\varepsilon_{c p} / 3 \\
\frac{1}{2} \sigma_{c p}\left[1+\frac{\varepsilon}{\varepsilon_{p c}}\right] & \varepsilon \geq \varepsilon_{c p} / 3\end{cases}
\end{aligned}
$$




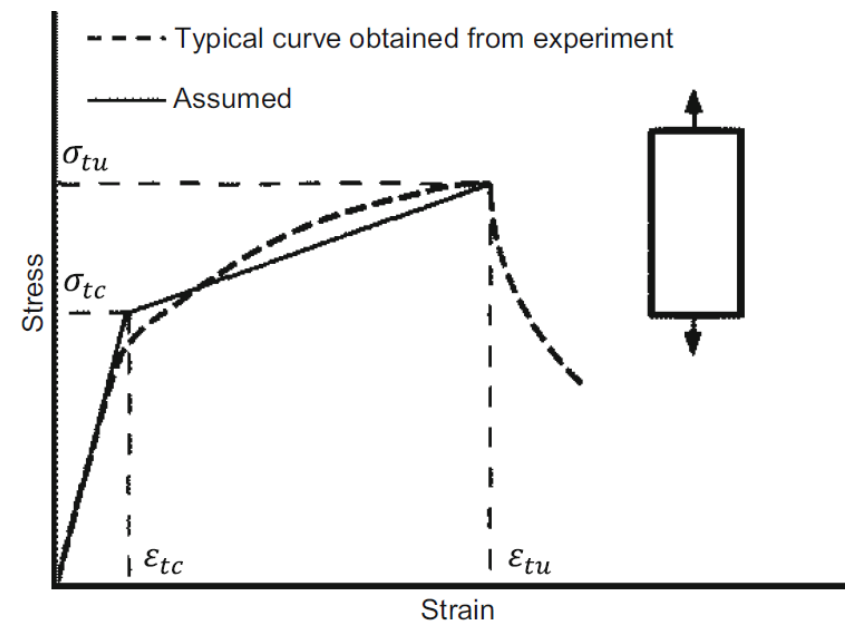

Fig. 11. Bi-linear representation of tensile stress-strain relation of ECC.

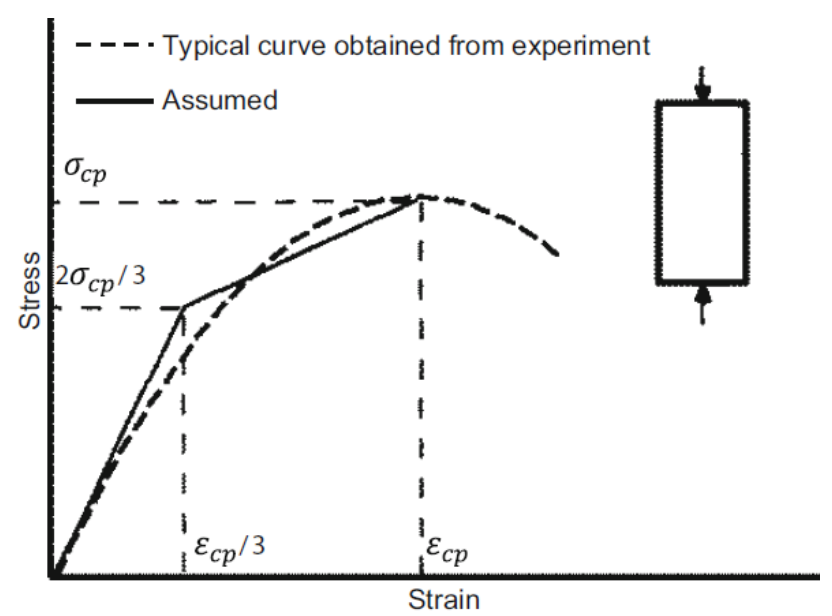

Fig. 12. Bi-linear representation of compressive stress-strain relation of ECC.

By considering a linear profile of strain distribution in the cross-section, the principle of beam curvature can be used to express the flexural moment as well as the tensile stain within the base of beam, by applying the equilibrium of forces and moments as shown in Fig. 13 [14]. When the tensile stain extents to the maximum strain capacity $\varepsilon$ ut failure of beam occurs. Based on the parametric values of the experimental records, the relationship between estimated flexural stress against deflection curve is shown in Fig. 14. It is shown that there is a coincide between the prediction of the model and the experimentally obtained flexural beam behavior. This model predicts that the deflection hardening under flexural loading of ECC beams and slabs is ensured by response of ECC's tensile strain-hardening in direct tension test, which proves consistency with most of the experimental observations.

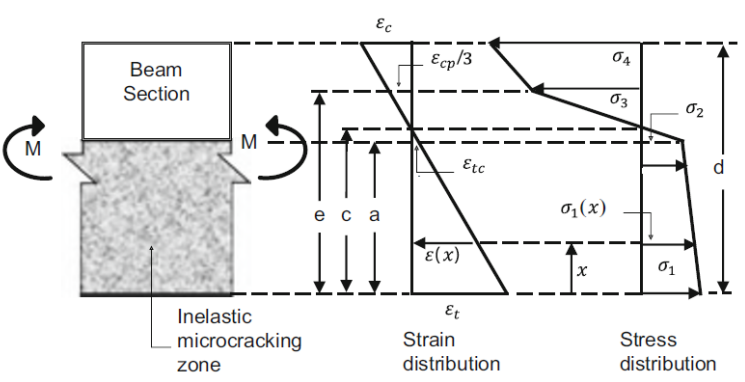

Fig. 13. Distribution of stress-strain in ECC beam cross section.

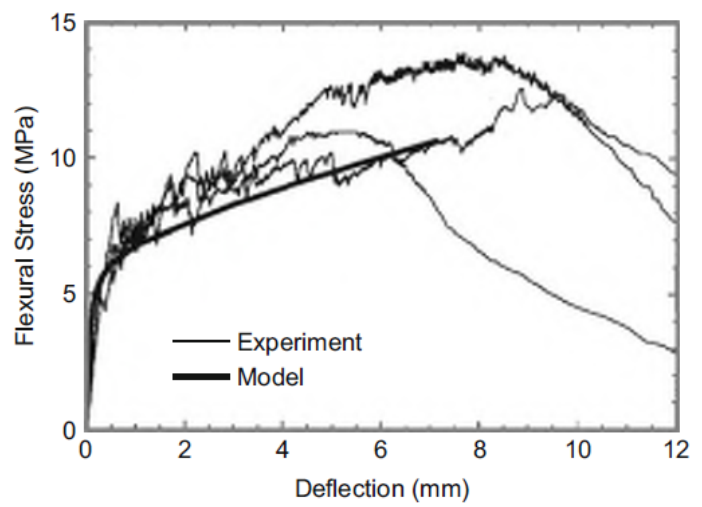

Fig. 14. Predicted model vs flexural behavior from experiment data for an ECC beam.

For ECC material, the model provides insights into the proportion of the flexural strength or MOR to first crack strength otc as shown in Fig 15, for a specified tensile strength/first crack ratio. Modelling of PE-ECC with ratio of $\sigma \mathrm{tu} / \sigma \mathrm{tc}=1.84$, the estimated ratio of MOR/ $\sigma \mathrm{tc}$ was greater than 4 . likewise, the modeling with ratio of $\sigma \mathrm{tu} / \sigma \mathrm{tc}=1.5$ for PVA-ECC, MOR/ $\sigma \mathrm{tc}$ was equal to 3.5. on the other hand, with perfectly elastic-plastic material, this ratio is equal to 3.0 for tension and compression as for metals; also the ratio is ranged from 1 to 3 for the case of tension strain-hardening, depending on softening ratio. The hardening strain in tension is responsible for MOR/otc magnification of ECC as shown in Fig. 15. The precise value of the ratio of MOR/ otc is therefore based on the individual ECC's compressive behavior.

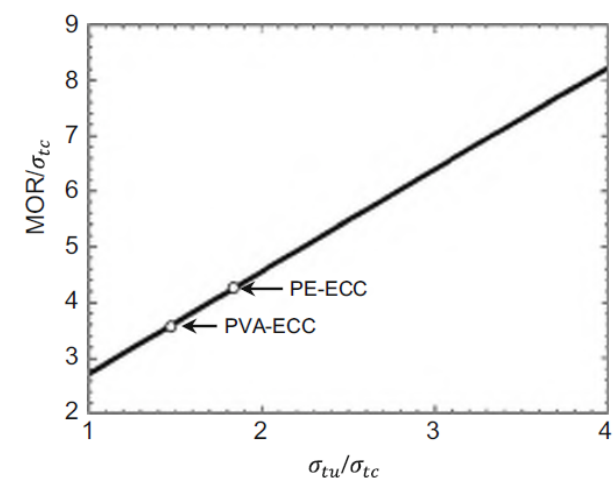

Fig. 15. (MOR/ $/ \mathrm{tc})$ vs. $\sigma \mathrm{tu} / \sigma \mathrm{tc}$ of an ECC beam 
- Behavior of Reinforced ECC Beams Under Flexure: Szerszen, Szwed [23] modelled the flexural performance of ECC beams with traditional steel reinforcement. In his model, the response of ECC material was simplified in a conservative way in tension and compression as elastic-perfectly plastic behavior similar to conventional steel reinforcement. Presuming that plane section stay plane and use equilibrium of forces and moments within the section, a derivation for the moment-curvature solution if formed for $\mathrm{R} / \mathrm{ECC}$ beams. By substantiating the observations from experiments for the samples of R/ECC, while an ideal bond between steel and ECC was considered. From Fig. 16 five phases of different levels for beam the beam deformity are identified. The moment-curvature was predicted by normalizing the elastic part in the momentcurvature as shown in Fig. 17, for the different reinforcement levels considered $\rho=0, \rho_{-} T, \rho \_B, \rho \_$C. It was noticed that beam failure is controlled by depleting compression strain $\varepsilon \_$uc for the ECC when the ratio of reinforcement is between 0 and $\rho \_$T.Once the ultimate failure of the beam is controlled by consuming the ECC compressive strain $\varepsilon_{-}$uc capability. Failure of ECC in compression and plastic yielding of steel is simultaneously achieved when $\rho=\rho$ C. Finally, with $\rho$ $>\rho \_C$ Steel reinforcement stays elastic all over. The following observations on R/ECC beam behavior can be extracted based on this model [6]:

- In R/ECC beams, no sudden load drop appears, as can occur in lightly reinforced $\mathrm{R} / \mathrm{C}$ beams. Alternatively, deflection hardening is anticipated.

- Due to ECC's ability to sustain load carrying capacity after the first crack, the flexural stiffness in R/ECC beams in post-cracked Phase II is still higher than that of $\mathrm{R} / \mathrm{C}$ beams despite ECC's lower Young's module compared to conventional concrete.

- R/ECC beam has always higher ductility than $\mathrm{R} / \mathrm{C}$ beam.

Fig. 17 represents the moment-curvature diagram can be used as a design guide for designing beams and one-way slab elements.

a)

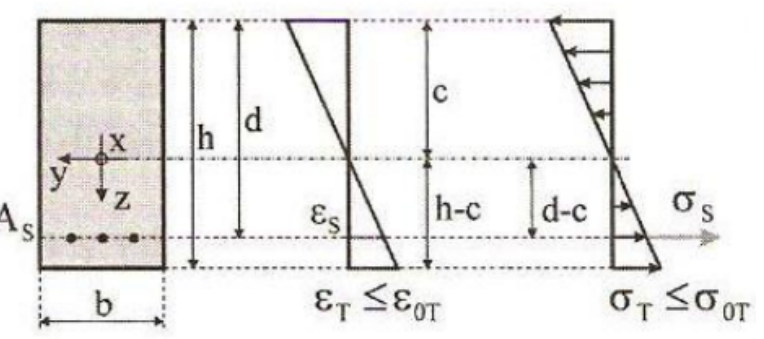

b)

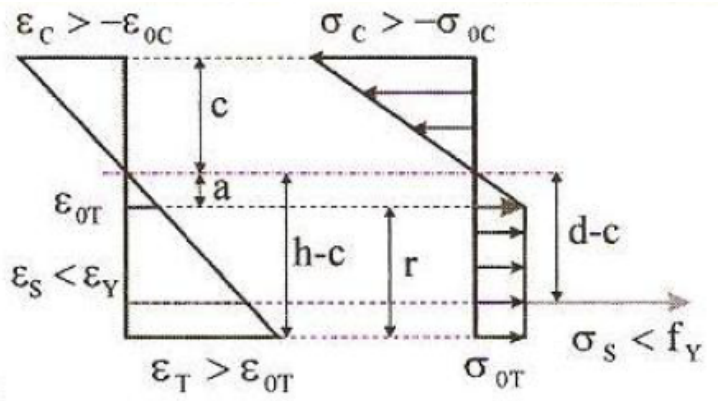

c)

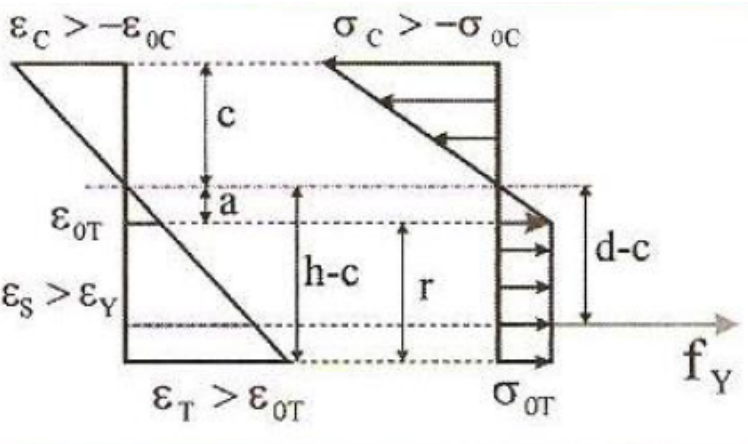

d)

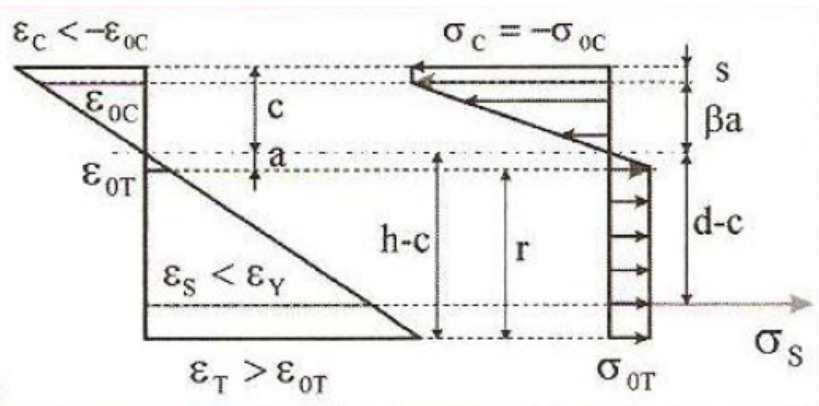

e)

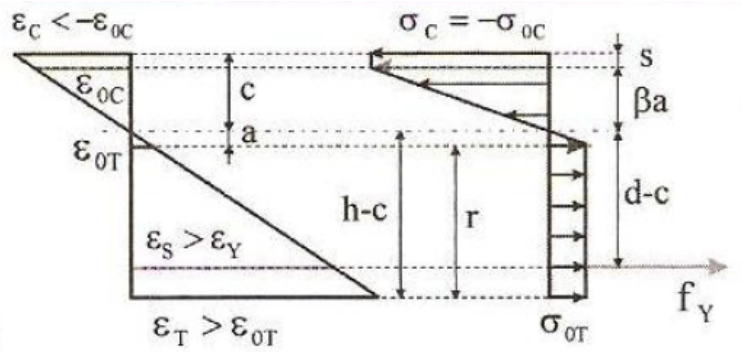

Fig. 16. (a) Phase I: All materials are elastic; (b) Phase II: ECC elasticplastic in tension; (c) Phase III: ECC elastic-plastic in tension and steel yields; (d) Phase IV: ECC elastic-plastic in tension and compression and elastic steel; (e) Phase V: ECC and steel elastic-plastic. 


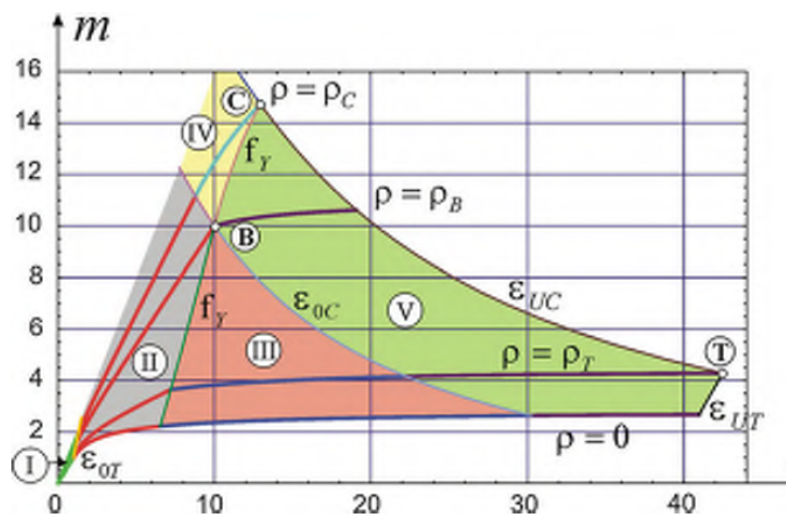

Fig. 17. Model predicted moment-curvature $(\mathrm{m}-\mathrm{k})$ relationship for $\mathrm{R} / \mathrm{ECC}$ beam, for four characteristic reinforcement ratios $\rho=0, \rho \mathrm{T}, \rho \mathrm{B}, \rho \mathrm{C}$. The five phases (I to V) correspond to those in Fig. 16.

From the experimental tests of ECC composite in uniaxial compression and tension, the predicted stress and stress magnitudes and are used in the following computational process. The Modulus of Elasticity (Ec) and the compressive strength $\left(\mathrm{f} \mathrm{c}^{\wedge{ }^{\prime \prime}}\right)$ were calculated as follows [23]: The compressive strength $f_{-} \mathrm{c}^{\wedge}=60 \mathrm{MPa}$, concrete tensile strength $\sigma$ oT $=5.3 \mathrm{MPa}$, the presumed structural compressive strength, $\sigma \_\mathrm{oC}=0.88 \mathrm{f} \mathrm{c}^{\wedge^{\prime}}=53$ $\mathrm{MPa}$. Characteristic properties were measured for elastic limit strains as: $(\varepsilon$ oT $=\sigma$ oT $/ \mathrm{Ec}=0.0003)$, and $(\varepsilon$ oc $=\sigma$ oc/ $/ \mathrm{Ec}=0.003)$. Compressive and tensile ultimate strains are estimated as: $(\varepsilon \mathrm{UC}=0.0045$ and $\varepsilon_{-} \mathrm{UT}=0.033$ ). Depending up on these quantities, some simple dimensionless parameters for the material can be found: $\beta=(\sigma \circ C / \sigma$ oT $)=10, \lambda=(\varepsilon$ UC $/ \varepsilon$ oc $=1.5$ ) , and $\alpha=\left(\varepsilon_{-} \mathrm{UT}^{-} / \varepsilon_{-} \mathrm{oT}=110\right)$. While material properties for steel reinforcement are: $\mathrm{Es}=20 \mathrm{GPa}$, fy $=$ $420 \mathrm{MPa}$, and $\varepsilon \mathrm{y}=0.00021$. Then, the modulus ratio $\mathrm{n}$ $=(\mathrm{Es} / \mathrm{Ec}=11 . \overline{4})$, and $\gamma=\varepsilon \mathrm{y} / \varepsilon 0 \mathrm{~T}=7.0 \mathrm{can}$ be computed. The concrete cover ratio for this analysis is considered to be: $\delta=0.85$. The failure balance factor is $\lambda$ Bal $=1.6$, which describes the failure to be compression controlled for cross sections of slightly reinforced. The ratio of reinforcement used are: $\rho \_B=$ $2.54 \%, \rho \_\mathrm{C}=4.34 \%$.

Fig. 17 shows the moment and curvature of different ratios of steel reinforcement, in which the explanation of characteristic boundaries and points occurred. Curvature and moment characteristic values are: $\mathrm{kB}=$ $10.00, \mathrm{MB}=10.00 \mathrm{McE}, \mathrm{kC}=12.94 \mathrm{kcE}, \mathrm{MC}=14.73$ McE. For the material data provided, $\lambda<\lambda$ Bal, the failure controlled by compression For un-intensified cross-section. The ultimate curvature and moment capacities for un-reinforced cross-section were: $\mathrm{kUC}=$ $57.75, \mathrm{mUC}=2.70$.

An increase in moment capacity due to the amount of reinforcement added is easy to read from the Fig. 17, And also the reduction of curvature ductility as a measure of the reinforcement ratio. Curves are given in Fig. 17 Describe specifically that there is no sudden decrease in efficiency after the first cracking. A sudden drop in the capacity of the moment is common for ordinary concrete, particularly for sections with light reinforcement [24]. For ECC matrix, the momentcurvature curves imply hardening behavior over the entire range of curvatures up to the ultimate capacity. This takes place due to the ECC material's continuous tensile load capability above its elastic limits. The depth of the compression zone is presented in Fig 18-a, depending on the curvature and reinforcement ratio. In phases I, III and V, for slightly reinforced sections, a rapid decrease of the compression zone in the cross section is observed. For highly reinforced sections, the compression area, with low curvature ductility defined by sudden compression failure mode, remains at a relatively constant level. In Fig. 18-b, the plots represent the curvature function for crushing zones in compression and tension. Rapid progress in phase II is observed of the cracking zone. While in phases III, IV and $\mathrm{V}$, the progress in zone of cracking as in phase II and become stable for section of high reinforcement in which rapid development of crushing zones can be seen especially within phase IV that reflects a mode of brittle failure.
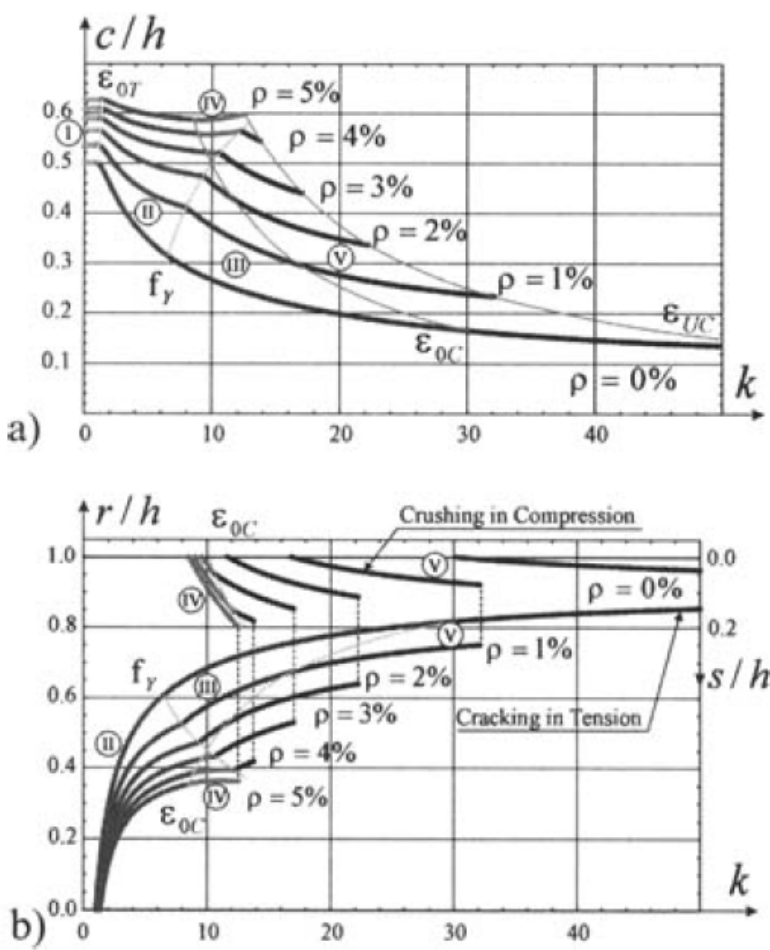

Fig. 18. a) Compression zone depth; b) Cracking and crushing zones development.

\section{Applications for Design of BeAm With ECC AND ORDINARY CONCRETE}

In this section, an example is demonstrating to calculate the moment capacity for two beams made with ECC and ordinary concrete, and an identical cross-sectional area and reinforcement ratio equal to the maximum permitted by ACI 18 Code, which 
was used to ensure a mode of ductile failure. This limit should not be more $0.75 \rho_{b}$, where $\rho_{b}$ is the balance reinforcement ratio $=4.74 \%$. for beam made with ordinary concrete, and for ECC beam this ratio is $5 \%$. The compressive strength for both ECC and ordinary concrete was kept the same and equals to 60 $\mathrm{MPa}$, and steel reinforcement yield strength $f_{y}=420$ (Grade 60) steel is used.

The percentage of reinforcement used in both beams, $\rho$, is assumed to be equal to, in the design calculation below.

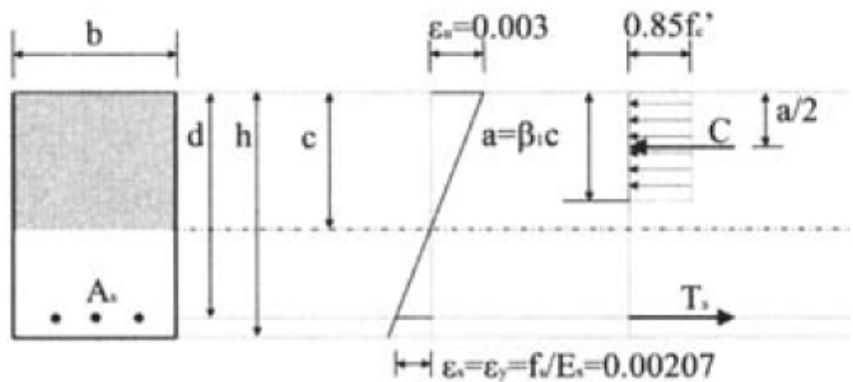

Fig. 19. cross-section of ordinary concrete beam, stress and strain distribution.

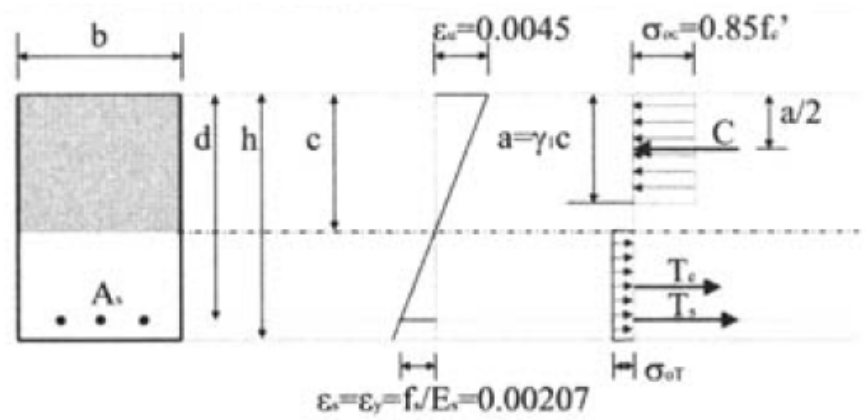

Fig. 20. cross-section of an ECC beam, stress and strain distribution.

From Fig. 19, the moment capacity is calculated according to ACI 318 Code for ordinary concrete beam

$$
\begin{aligned}
& C=0.85 f_{c}^{\prime} \times a \times b \\
& T_{s}=A_{s} \times f_{y} \\
& C=T, \Rightarrow a \frac{A_{s} \times f_{y}}{0.85 f_{c}^{\prime} \times b} \\
& \begin{aligned}
\mathrm{A}_{\mathrm{s}}=0.035 \times \mathrm{b} \times \mathrm{d}=0.035 \times 15 \times 18.5=9.71 \mathrm{in}^{2} \\
a=\frac{9.71 * 60000}{0.85 * 8700 * 15}=5.25 \mathrm{in} \\
\text { Mcap }_{\text {oc }}=\text { As } f_{y}\left(d-\frac{a}{2}\right) \\
\quad=9.71 \times 60000 \times\left(18.5-\frac{5.25}{2}\right) \\
\quad=9,248,775 \mathrm{Ib}-\mathrm{in}
\end{aligned}
\end{aligned}
$$

The analysis of ECC beam moment capacity presented below is adjusted to take into account the strain and stress capacity of the composite in the tension zone compared to the normal code procedure (Fig. 20). $\beta 1$ parameter represents the stress block for ordinary concrete its value is 0.65 for $f_{c}^{\prime}=8700 \mathrm{psi}$, this parameter is recalculated for ECC material, and is equivalent to 0.66 .

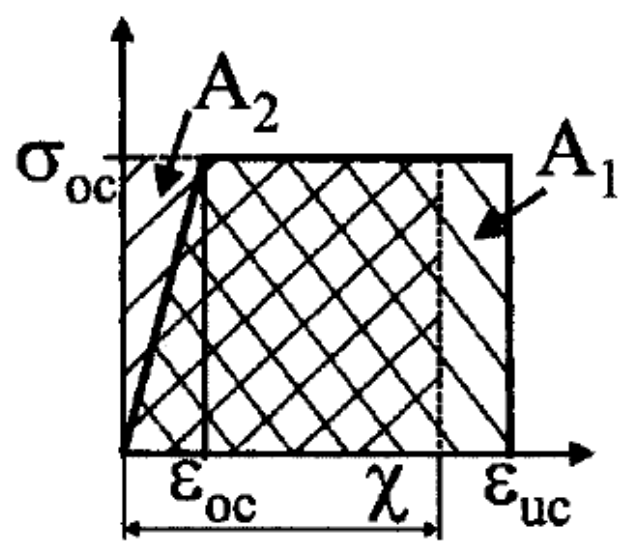

Fig. 21. : A1 and A2 functions

$$
\begin{aligned}
& \mathrm{A}_{1}=\sigma_{o c} \times \varepsilon_{o c} * 0.5+\left(\varepsilon_{u c}-\varepsilon_{o c}\right) \sigma_{o c} \\
& \varepsilon_{o c}=\frac{\sigma_{o c}}{E_{c}}=0.00303 \\
& \mathrm{~A}_{2}=\sigma_{o c} \times \chi \\
& \text { Then } \\
& \chi=\frac{\sigma_{o c} \times \varepsilon_{o c} \times 0.5+\left(\varepsilon_{u c}-\varepsilon_{o c}\right) \sigma_{o c}}{\sigma_{o c}} \\
& =0.00303 \times 0.5+(0.0045-0.00303) \\
& =0.00299 \\
& \gamma_{1}=\frac{\chi}{\varepsilon_{u c}}=\frac{0.00299}{0.0045}=0.66 \\
& a=\gamma_{1} c=0.66 c \\
& \mathrm{~A}_{\mathrm{s}}=9.71 \mathrm{in}^{2} \\
& \mathrm{C}=0.85 f_{c}^{\prime} a b \\
& \mathrm{~T}_{\mathrm{c}}=\sigma_{o T} \times(h-c) b \\
& \mathrm{~T}_{\mathrm{s}}=\mathrm{A}_{\mathrm{s}} \mathrm{f}_{\mathrm{y}} \\
& \mathrm{C}=\mathrm{T}_{\mathrm{c}}+\mathrm{T}_{\mathrm{s}} \\
& 0.85 f_{c}^{\prime} \times 0.66 b \times c=\sigma_{o T} \times(h-c) b+\mathrm{A}_{\mathrm{s}} \mathrm{f}_{\mathrm{y}} \\
& \Rightarrow c=\frac{770 \times 20 \times 15+9.71 \times 60000}{.85 \times 8700 \times 0.66 \times 15+770 \times 15}=9.6 \mathrm{in} \\
& a=0.66 \times 9.6=6.3 \text { in. } \\
& M_{\text {cap }}=T_{c} \times\left[\frac{h-c}{c}+c-\frac{a}{2}\right]+T_{s}\left[d-\frac{a}{2}\right] \\
& M_{\text {cap }}=\sigma_{o T}(h-c) b\left[\frac{h-c+2 c-a}{2}\right]+\mathrm{A}_{\mathrm{s}} \mathrm{f}_{\mathrm{y}}\left[d-\frac{a}{2}\right] \\
& M_{\text {cap }}=\frac{1}{2}\left[\sigma_{o T}(h-c) \times(h+c-a) b+\text { As fy }(2 \mathrm{~d}-\mathrm{a})\right] \\
& M_{\text {cap }}=\frac{1}{2}[770(20-9.6)(20+9.6-6.3) 15 \\
& +9.7 \times 60000(2 \times 18.5-6.3)] \\
& =10,342,308 \mathrm{lb}-\text { in }
\end{aligned}
$$


This indicates an increase in moment capacity of the beam of about $12 \%$ when comparing between ECC material and ordinary concrete. Also it has been concluded that the above analysis is very sensitive and ECC contribution is very significant especially for lower reinforcement percentage which lead to an increase in the tensile zone. This significance can be outlined if ECC incorporated in concrete bridge slabs, when reinforcement ratio is low (about $0.3 \%$ ), if the above calculations are repeated for a slab thick of 7.5in. ECC bridge deck, this will give an increase of $230 \%$ of the moment capacity when compared to an ordinary concrete deck slab.

\section{CONCLUSIONS}

- After the invention of ECC as a new concrete content, the creation of constitutive models for ECC has made great strides. In structural applications, the willingness to take benefit of ECC's special characteristics has prompted their growth. These models vary from traditional constitutive models of normal concrete in that, when loaded beyond the elastic range, they were built explicitly to satisfy the tensile strain-hardening properties of ECC.

- The phenomenological models addressed are also support for loading of monotonic forms. While their applications to particular systems have shown their flexibility, limitations have also been identified. Compared to experimental findings, the propensity to predict a stiffer and stronger structural response is among these. This was due to the fact that only in the opening mode, but not in the sliding mode, would the numerous cracks deform. When main stress rotation occurs during structural loading, the latter can be triggered, especially in structures that may experience shear-critical failure

- Despite their inherent restrictions, it is clear that constitutive models are an important instrument in the quantitative link between the structural design and the design of ECC materials in promoting a deeper understanding of structural behavior both in the mechanical sense and in the sense of durability. The ageing of ECC constitutive models can be expected to allow more productive and wider use of such a material in critical infrastructures in the future.

\section{REFERENCES}

[1] Bentur, A. and S. Mindess, Fibre reinforced cementitious composites. 2006: Crc Press.

[2] O’ Neil, E.F., B.D. Neeley, and J.D. Cargile, Tensile properties of very - high - strength concrete for penetration - resistant structures. Shock and Vibration, 1999. 6(5, 6): p. 237-245.
[3] O'Neil III, E.F., On engineering the microstructure of high-performance concretes to improve strength, rheology, toughness, and frangibility. 2008.

[4] Chanvillard, G. and S. Rigaud. Complete characterization of tensile properties of Ductal UHPFRC according to the French recommendations. in Proceedings of the 4th International RILEM workshop High Performance Fiber Reinforced Cementitious Composites. 2003.

[5] Graybeal, B.A., Material property characterization of ultra-high performance concrete. 2006, United States. Federal Highway Administration. Office of Infrastructure ....

[6] Li, V.C., Engineered Cementitious Composites (ECC): Bendable Concrete for Sustainable and Resilient Infrastructure. 2019: Springer.

[7] Li, V., The Design of Cementitious Composites for Civil Engineering Applications. J. Struct. Mech. Earthquake Eng., JSCE, 1993. 10(2): p. 3748.

[8] Li, V.C., S. Wang, and C. Wu, Tensile strain-hardening behavior of polyvinyl alcohol engineered cementitious composite (PVA-ECC). ACI Materials Journal-American Concrete Institute, 2001. 98(6): p. 483-492.

[9] Li, V.C., On engineered cementitious composites (ECC). Journal of advanced concrete technology, 2003. 1(3): p. 215-230.

[10] Zhang, Q., R. Ranade, and V.C. Li, Feasibility study on fire-resistive engineered cementitious composites. ACI Materials Journal, 2014. 111(6): p. 651.

[11] Ranade, R., et al., Composite Properties of High-Strength, High-Ductility Concrete. ACI Materials Journal, 2013. 110(4).

[12] Yokota, H., K. Rokugo, and N. Sakata. JSCE recommendations for design and construction of high performance fiber reinforced cement composite with multiple fine cracks. in High Performance Fiber Reinforced Cement Composites. 2008.

[13] Wang, S. and V.C. Li. Polyvinyl alcohol fiber reinforced engineered cementitious composites: material design and performances. in Proc., Int'l Workshop on HPFRCC Structural Applications, Hawaii. 2005. Citeseer.

[14] Maalej, M. and V.C. Li, Flexural/tensile-strength ratio in engineered cementitious composites. Journal of Materials in Civil Engineering, 1994. 6(4): p. 513-528.

[15] Ranade, R., Advanced cementitious composite development for resilient and sustainable infrastructure. 2014, University of Michigan.

[16] Zhou, J., J. Pan, and C.K. Leung, Mechanical behavior of fiber-reinforced engineered cementitious composites in uniaxial compression. Journal of materials in civil engineering, 2015. 27(1): p. 04014111.

[17] Wang, S., Micromechanics based matrix design for engineered cementitious composites. 2005: University of Michigan.

[18] Zhang, Q. and V.C. Li, Development of durable spray-applied fireresistive Engineered Cementitious Composites (SFR-ECC). Cement and Concrete Composites, 2015. 60: p. 10-16.

[19] Zhang, Q. and V.C. Li. Ductile Fire-Resistive Material for Enhanced Fire Safety Under Multi-Hazards-A Feasibility Study. in Structures Congress 2014. 2014.

[20] Li, V.C., Engineered cementitious composites (ECC) material, structural, and durability performance. 2008.

[21] Yu, K.-Q., et al., Development of ultra-high performance engineered cementitious composites using polyethylene (PE) fibers. Construction and Building Materials, 2018. 158: p. 217-227.

[22] Li, V.C., Integrated structures and materials design. Materials and Structures, 2007. 40(4): p. 387-396.

[23] Szerszen, M.M., A. Szwed, and V.C. Li, Flexural response of reinforced beam with high ductility concrete material. 2006.

[24] Bosco, C., A. Carpinteri, and P. Debernardi, Minimum reinforcement in high-strength concrete. Journal of Structural Engineering, 1990. 116(2): p. 427-437. 